\title{
INTRAOPERATIVE MANAGEMENT OF PHEOCHROMOCYTOMA RESECTION- A CASE REPORT
}

\author{
Shreyas Rao ${ }^{1}$, Akhil Bhallaㄹ, Anam Amin Kazi ${ }^{3}$, Aparna Amar Ruparel ${ }^{4}$, Amit Nagpal ${ }^{5}$
}

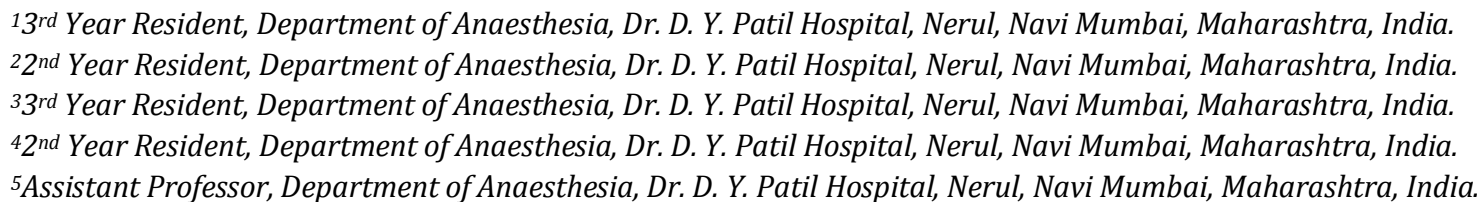

HOW TO CITE THIS ARTICLE: Rao S, Bhalla A, Kazi AA, et al. Intraoperative management of pheochromocytoma resection- a case report. J. Evolution Med. Dent. Sci. 2019;8(04):283-284, DOI: 10.14260/jemds/2019/62

\section{PRESENTATION OF CASE}

A 36 years old female, weighing $55 \mathrm{~kg}$ presented with the complaint of palpitation since one month. On general examination, she had a pulse of $110 / \mathrm{min}$ and blood pressure $160 / 100 \mathrm{mmHg}$. There was a palpable mass in her left hypochondrium attached to the kidney. During investigations, CECT abdomen showed a large heterogenous supra renal mass measuring $73 \times 71 \times 86 \mathrm{~mm}$. On systemic examination, findings were normal. Her $\mathrm{Hb}$ was $11.0 \mathrm{gm} / \mathrm{dl}$ and all other investigations were in normal limits. The chest $\mathrm{x}$-ray PA view was normal, 2-D echocardiography showed ejection fraction $62 \%$, trivial MR and normal chambers and valves.

\section{CLINICAL DIAGNOSIS}

Pheochromocytoma

\section{PATHOLOGICAL DISCUSSION}

Suspecting pheochromocytoma, following investigations were done to confirm the diagnosis of pheochromocytoma. The serum cortisol level was $0.66 \mathrm{mg} / \mathrm{dl}$ and DHEAS was $65 \%$. Her urine VMA levels were $35.88 \mathrm{mg} / 24 \mathrm{hrs}$.

\section{DISCUSSION OF MANAGEMENT}

It was decided to treat the patient surgically. ${ }^{1}$ Tab Prazosin 5 mg BD and tab Propranolol $40 \mathrm{mg}$ QID were started immediately and surgery was planned after 2 weeks to reduce risk of intra operative hypertensive crisis and arrhythmias. She was a known case of hypertension for 6 months and was taking tab. Nicardia 20 BD. She was a known case of diabetic mellitus for 15 days which was controlled on tab. Metformin $500 \mathrm{mg}$ BD. Patient was explained and written consent was obtained. Preoperatively high-risk consent was taken, and ICU bed was reserved with ventilatory support. On shifting to the operation theatre, monitors were connected (ECG, BP and $\mathrm{SpO}_{2}$ ) and an IV drip was started. A triple lumen central venous catheter was inserted, arterial line inserted in left radial artery. Before the surgery her pulse rate was 105/min, BP 155/85 mmHg with SpO2 100\%. She was given Magnesium sulphate $1 \mathrm{gm}$ IV over 10 minutes. ${ }^{2}$ An epidural catheter was inserted at L2-L3 interspace with loss of resistance technique and fixed at 9 th mark, for peri and post-

'Financial or Other Competing Interest': None.

Submission 07-12-2018, Peer Review 18-01-2019,

Acceptance 22-01-2019, Published 28-01-2019.

Corresponding Author:

Dr. Shreyas Rao,

B/2/4, Kripanagar,

Irlas. V. Road, Ville Parle West,

Mumbai-400056, Maharashtra, India.

E-mail: drshreyasrao@gmail.com

DOI: $10.14260 /$ jemds $/ 2019 / 62$ operative analgesia. She was premedicated with inj. Midazolam $1 \mathrm{mg}$ and inj. fentanyl $100 \mu \mathrm{g}$. The patient was preoxygenation with $100 \% \mathrm{O}_{2}$ for three minutes and induction was done with inj. propofol $100 \mathrm{mg}$, vecuronium bromide $0.1 \mathrm{mg} / \mathrm{kg}$ and she was intubated with a $7.5 \mathrm{~mm}$ cuffed ETT. sevoflurane in $\mathrm{O}_{2}: \mathrm{N}_{2} \mathrm{O}$ (1:1) was used for maintenance of anaesthesia. ${ }^{3}$ After entering the peritoneum, while the abdominal mass was being explored, the BP suddenly rose up to $196 / 120 \mathrm{mmHg}$ and the heart rate rose to $130 / \mathrm{min}$, so sevoflurane was increased from $2 \%$ to $4 \%$. To combat the further reduction in $\mathrm{BP}$ and $\mathrm{HR}$, nitroglycerine infusion was started at the rate of $0.5 \mu \mathrm{g} / \mathrm{kg} / \mathrm{min}$ and gradually, was later increased to $1 \mu \mathrm{g} / \mathrm{kg} / \mathrm{min}$. BP was not controlled so inj. labetalol $5 \mathrm{mg}$ IV was given. 4 The BP dropped to $180 / 100 \mathrm{mmHg}$ and HR reduced to $115 / \mathrm{min}$. A repeat dose of inj. Labetalol $5 \mathrm{mg}$ IV was given. After clamping of suprarenal vein there was sudden fall in BP to 90/60 mmHg. Nitroglycerin infusion was stopped and noradrenaline infusion was started at $0.15 \mu \mathrm{g} / \mathrm{kg} / \mathrm{min}$. The surgically resected mass was sent for histopathology. BP continued to stay low $(72 / 50 \mathrm{mmHg})$, thus the noradrenaline infusion was increased to $0.2 \mu \mathrm{g} / \mathrm{kg} / \mathrm{min}$ and continued. To improve the left ventricular filling, intravenous fluids were given. The estimated total blood loss was around $500 \mathrm{ml}$. At the end of surgery, the patient was shifted to ICU and kept on mechanical ventilation with noradrenaline support. He total urine output was $300 \mathrm{ml}$. In ICU, patient was put on pressure control mode with $\mathrm{FiO}_{2}$ 0.5, PEEP $4 \mathrm{cmH}_{2} \mathrm{O}$ and $\mathrm{RR} 14 / \mathrm{min}$. ABG report showed $\mathrm{pH}$ 7.4, $\mathrm{PCO}_{2} 40, \mathrm{PO}_{2} 155$ and $\mathrm{HCO}_{3} 24$. Overnight, mechanical ventilation was continued. On second post-op day, her HR was 100/min, BP 105/76 mmHg, and on auscultation, the chest was clear. So, it was decided to wean her off ventilator and gradually lower the inotrope support. When the patient was responding to verbal commands and fully awake, ventilator settings were changed to continuous positive pressure mode. A T-piece trial was given, and the patient remained comfortable and tolerated the trial well, so was extubated after adequate suctioning. The patient was observed in ICU for five more days and was shifted to the ward on seventh postop day. Histopathology report was later received, which confirmed the diagnosis of pheochromocytoma.

\section{DISCUSSION OF ANAESTHETIC MANAGEMENT}

The WHO classification of endocrine tumours defines pheochromocytoma (PCC) as a catecholamine-producing intra-adrenal tumour arising from the chromaffin cells. ${ }^{5}$

Pheochromocytomas represent significant management challenges to the anaesthesiologists. Preoperative evaluation of these patients is key to successful perioperative management. Roizen criteria can be used to objectively gauge 
the efficacy of adequate preoperative alpha-blockade, and they include: No in-hospital blood pressure $>160 / 90 \mathrm{mmHg}$ for $24 \mathrm{~h}$ prior to surgery; No orthostatic hypotension with blood pressure $<80 / 45 \mathrm{mmHg}$; No ST or T wave changes for 1-week prior to surgery; No more than 5 premature ventricular contractions per minute. Alpha blockade has been the mainstay of preoperative preparation for pheochromocytoma patients. In most centers, a combination of alpha-adrenergic and beta-adrenergic blockade and calcium channel blockers, in addition, are routinely used. The alpha-adrenergic blockade is typically administered starting 10-14 days preoperatively which, in addition to normalizing blood pressure, also aids in expanding the highly contracted intravascular volume, especially in the higher risk pheochromocytoma patients. Relief from anxiety prior to anaesthetic induction is a key component, as apprehension can predispose to catecholamine surges. Ideally, a long acting benzodiazepine such as lorazepam or diazepam administered the night before the operation (As tolerated) in addition to a judicious dose of IV midazolam prior to transfer to the operating suite creates a calm patient less prone to hypertensive crises at induction. Anaesthetic induction is one of the most critical portions of the procedure, with every effort being made to limit the hemodynamic stresses of direct laryngoscopy. Agents commonly used include propofol and etomidate. Ketamine is usually avoided due to its sympathomimetic effects. Propofol has been documented to be safe in these patients; etomidate has the advantage of conferring cardiovascular stability, especially in volumedepleted patients. For neuromuscular blockade vecuronium is the most widely used and preferred. Sevoflurane is most commonly used for pheochromocytoma excision. Intraarterial monitoring is the gold standard in the pheochromocytoma resection for beat-to-beat blood pressure monitoring. Central venous catheterization and monitoring is essential in these patients. Hypertension during resection may arise from positioning, skin incision, intubation and is usually transient and responds to quick therapy. Tumour manipulation usually generates a far more dramatic pressor response and usually associated with severe hemodynamic instability including significant reductions in cardiac output, left ventricular systolic and diastolic dysfunction. Prompt responses should include deepening the depth of anaesthesia and rapidly administering direct arterial vasodilators, sodium nitroprusside being the key drug in conjunction with nitroglycerin, to reduce preload. Communication with the surgeon is critically important before tumour manipulation is begun to reduce the likelihood of major hemodynamic events. As a result of catecholamine excess, hyperglycaemia is common and insulin infusion therapy, as indicated, should be the routine management in these patients. Sudden hypotension may also occur following ligation of the tumour which usually managed with massive fluid transfusion. DA-1, norepinephrine, and vasopressin have been used with success in refractory cases. Consideration should also be given to rapid steroid replacement in the hypotensive patient following bilateral adrenalectomies. Post-resection, all pheochromocytoma patients need intensive monitoring.

\section{FINAL DIAGNOSIS}

Pheochromocytoma.

\section{REFERENCES}

[1] Lenders JW, Pacak K, Walther MM, et al. Biochemical Diagnosis of Pheochromocytoma. Which test is best? JAMA 2002;287(11):1427-34.

[2] James MF, Cronjé L. Pheochromocytoma crisis: the use of magnesium sulfate. Anesth Analg 2004;99(3):680-6.

[3] O'Riordan JA. Pheochromocytomas and anesthesia. Int Anesthesiol Clin 1997;35(4):99-127.

[4] Eisenhofer G, Bornstein SR. Surgery: risks of hemodynamic instability in pheochromocytoma. Nat Rev Endocrinol 2010;6(6):301-2.

[5] Fleisher L, Mythen M. Anesthetic implications of concurrent diseases. In: Miller RD, Cohen NH, Eriksson LI, et al. eds. Miller's Anesthesia. $8^{\text {th }}$ edn. Philadelphia: Elsevier Saunders 2015: p. 1170. 